\title{
Simultaneous chromatographic analysis of Sofosbuvir/Ledipasvir in their combined dosage form: an application to green analytical chemistry
}

\author{
Ahmed Hemdan ${ }^{1}$ and Maya S. Eissa ${ }^{2^{*}}$ (D)
}

\begin{abstract}
Application of green solvents for developing green analytical methodologies has grown dramatically in the past few years. The "more hazardous reagents" are replaced by more "environment-friendly solvents" without affecting method performance. In the present study, two simple and accurate chromatographic methods were developed and validated for determination of the new antiviral combination sofosbuvir (SBR) and ledipasvir (LPV). The first adopted method is high-performance thin-layer chromatography coupled to densitometric determination where silica gel $60 \mathrm{~F}_{254}$ plates were used as the stationary phase. Whereas, the running mobile phase used was toluene: ethanol: ammonia (4:1:0.2, v/v/v). Reversed-phase high-performance liquid chromatography with ultraviolet detection was the second method developed. The column used was Inertsil $C_{18}$ column $(150 \times 4.6 \mathrm{~mm}, 5 \mu \mathrm{m})$ and the mobile phase was $20 \mathrm{mM}$ potassium dihydrogen orthophosphate (adjusted to $\mathrm{pH}=3$ using acetic acid): ethanol $(60: 40, \mathrm{v} / \mathrm{v})$ with a flow rate of $1.0 \mathrm{~mL} / \mathrm{min}$. The detection wavelength for both methods was $265 \mathrm{~nm}$. The validation of both methods was done according to $\mathrm{ICH}$ guidelines where both methods were found to be accurate, reproducible, and selective. The linearity range for HPTLC and RP-HPLC methods were 0.8-25.6 and 0.4-12.8 $\mu \mathrm{g} /$ band and $6.0-100.0$ and $4.0-80.0 \mu \mathrm{g} / \mathrm{mL}$ for sofosbuvir and ledipasvir, respectively. Comparison of the developed methods was done with reported HPLC method where no significant difference was found.
\end{abstract}

Keywords: Sofosbuvir/ledipasvir, HPTLC-densitometry, RP-HPLC-UV, Green analytical chemistry, Green solvents

\section{Introduction}

Sofosbuvir (SBR) is a new drug used for treating hepatitis $\mathrm{C}$ viral infection. Hepatitis $\mathrm{C}$ virus (HCV) infects the liver and has many complications which might need liver transplantation (Jacobson et al. 2010; Lavanchy 2011). The mode of action of the prodrug SBR is a nucleotide analog inhibitor of HCV nonstructural protein 5B (NS5B) (Keating and Vaidya 2014; Gorman et al. 2015). Ledipasvir (LPV) also is a new antiviral drug for the treatment of HCV. The combination of SBR and LPV for the treatment of HCV is approved by FDA in 2014 (Afdhal et al. 2014; Link et al. 2014; Pollack 2014). After literature survey, we found many chromatographic methods for the determination of the

\footnotetext{
*Correspondence: maya-shaaban@hotmail.com

${ }^{2}$ Department of Pharmaceutical Analytical Chemistry, Faculty of Pharmacy,

Egyptian Russian University, Cairo, Egypt

Full list of author information is available at the end of the article
}

combination such as LC-MS/MS (Rezk et al. 2016; Pan et al. 2016; Elkady and Aboelwafa 2016), RP-HPLC-DAD (Farid and Abdelwahab 2017), and dissolution studies using RP-HPLC (Zaman et al. 2016; Hassouna et al. 2017) and in dosage forms (Rote et al. 2017). Also, densitometric methods were reported (Salama et al. 2017; Baker et al. 2018). But we noticed that all the published methods utilize organic solvents which are hazardous or toxic to the environment.

In green analytical chemistry, hazardous chemicals are replaced with more eco-friendly solvents without affecting the overall performance of the method (Welch et al. 2010). To the best of our knowledge, no previous researches had been developed for the simultaneous determination of the suggested two-drug combination: SBR/LPV using alternative green solvents. So, our main challenge was to simultaneously 
determine both analytes using more eco-friendly solvents without affecting method performance. Therefore, two accurate and reproducible chromatographic methods for the simultaneous estimation of SBR/LPV in their binary laboratory-prepared mixtures and in their combined tablet dosage form using green solvents were first introduced in this work. ICH guidelines were followed for the complete validation of the developed methods (ICH 2005). Statistical comparison was applied with reported RP-HPLC method and no significant difference was found.

\section{Methods}

\section{Instruments}

- Linomat IV auto-sampler (Camag, Muttenz, Switzerland), Camag microsyringe $100 \mu \mathrm{L}$ (Hamilton, Bonaduz, Switzerland), Pre-coated silica gel aluminum plates $60 \mathrm{~F}_{254} 250 \mu \mathrm{m}$ thickness $20 \mathrm{~cm} \times 10 \mathrm{~cm}$ (E. Merck, Darmstadt, Germany), Twin-trough Automatic Developing Chamber ADC 2 chamber $20 \mathrm{~cm} \times 10 \mathrm{~cm}$ (Camag, Muttenz, Switzerland), Camag TLC scanner III S/N 130319 (Camag, Muttenz, Switzerland) operated using WinCATS software version 3.15.

- The HPLC System: Jasco (JASCO, Tokyo, Japan) model LC-Net II/ADC and a UV detector UV-2070 plus equipped with an isocratic pump PU-2080 plus and 4-line degasser DG-2080-54. The stationary phase was Inertsil $\mathrm{C}_{18}$ column $(150 \times 4.6 \mathrm{~mm}$, $5 \mu \mathrm{m})$. Data acquisition was performed by the use of ChromNAV software.

- pH meter (Jenway 3310, UK)

\section{Chemicals and solvents}

Ethanol (Sigma-Aldrich, Germany), toluene (Merck, Darmstadt, Germany), acetic acid (Riedel-de Haen, Seelze, Germany), ammonia (Merck, Darmstadt, Germany), and potassium dihydrogen phosphate (Merck, Darmstadt, Germany).

\section{Samples}

(a) Pure standard of SBR (with certified purity of $99.89 \pm 0.691)$

(b) Pure standard of LPV (with certified purity of $99.79 \pm 0.461)$

Both standards were kindly supplied by Memphis Co. for Pharmaceutical and Chemical Industries, Cairo, Egypt. Their chemical structures are presented in Fig. 1.

(c) Heterosofir Plus ${ }^{\circ}$ tablet dosage form-each tablet contains SBR (400 mg) and LPV (90 mg), manufactured by PHARMED Healthcare Co., Sadat City, Egypt.

\section{Standard solutions}

For HPTLC-densitometric method: stock standard solutions of SBR and LPV were prepared in ethanol to obtain concentrations of $2.0 \mathrm{mg} / \mathrm{mL}$ and $1.0 \mathrm{mg} / \mathrm{mL}$, respectively. For RP HPLC-UV method, the two previously prepared stock standard solutions for HPTLCdensitometric method for each drug were then subjected to further dilutions using the HPLC mobile phase to obtain two working standard solutions having concentrations of $200.0 \mu \mathrm{g} / \mathrm{mL}$ for SBR and $100.0 \mu \mathrm{g} / \mathrm{mL}$ for LPV.

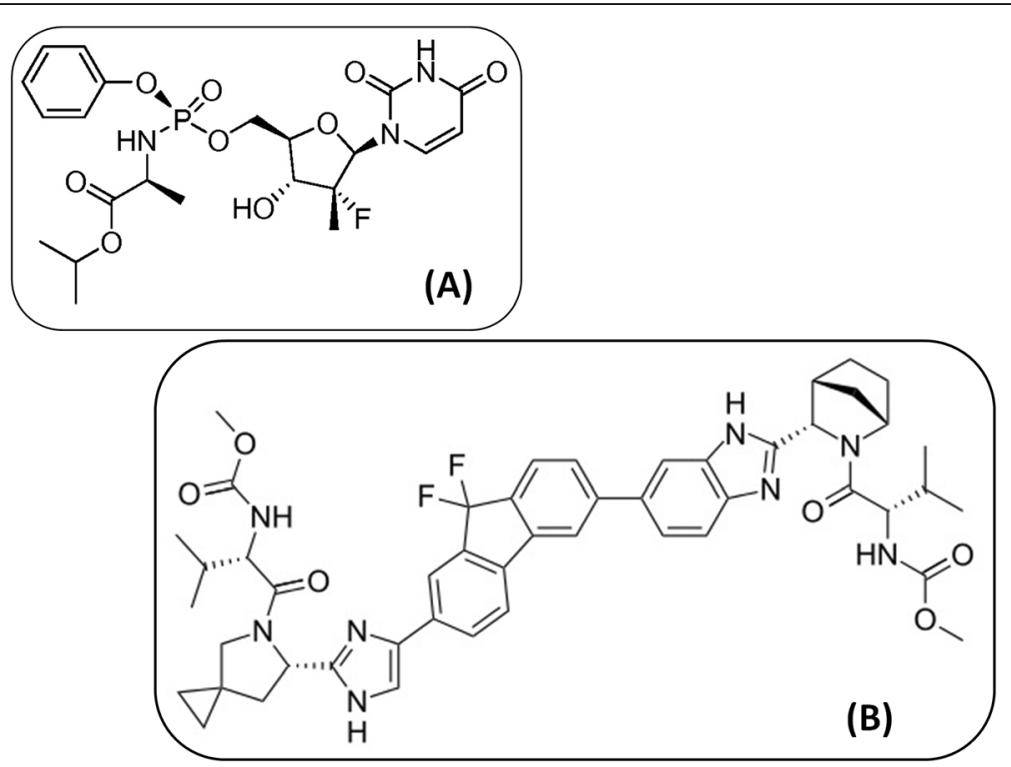

Fig. 1 Chemical structure of SBR (a) and LPV (b) 
All experiments were conducted away from direct sunlight and stock standard solutions were refrigerated up to 1 week.

\section{Chromatographic conditions HPTLC-densitometric method}

On a pre-coated silica gel aluminum plate $60 \mathrm{~F}_{254} 20 \mathrm{~cm} \times$ $10 \mathrm{~cm}$, samples from the prepared stock standard solutions were applied in the form of bands (6 mm width) by the Camag microsyringe $100 \mu \mathrm{L}$ using Camag Linomat IV autosampler. After chamber saturation, linear ascending development was carried out in $20 \mathrm{~cm} \times 10 \mathrm{~cm}$ twintrough Automatic Developing Chamber ADC 2 chamber by the use of a mobile phase system consisted of toluene: ethanol: ammonia $(4: 1: 0.2, \mathrm{v} / \mathrm{v} / \mathrm{v})$. As soon as the solvent front reached a pre-defined position, the plate was removed and was subjected to flow-optimized conditions to dry. The experimental wavelength selected for detection and quantification was $265 \mathrm{~nm}$.

\section{RP HPLC-UV method}

The stationary phase was Inertsil $C_{18}$ column $(150 \times$ $4.6 \mathrm{~mm}, 5 \mu \mathrm{m})$ and the mobile phase was $20 \mathrm{mM}$ potassium dihydrogen orthophosphate (adjusted to $\mathrm{pH}=3$ using acetic acid): ethanol (60:40, v/v). Injection volume was $10 \mu \mathrm{L}$ and the flow rate was adjusted at $1.0 \mathrm{~mL} /$ min and the UV detection was performed at $265 \mathrm{~nm}$. Data manipulation was carried out using ChromNAV software.

\section{Construction of calibration curves HPTLC-densitometric method}

Onto the pre-coated silica gel aluminum plates $60 \mathrm{~F}_{254}$ $20 \mathrm{~cm} \times 10 \mathrm{~cm}$, accurate volumes were transferred from the stock standard solution of SBR $(2.0 \mathrm{mg} / \mathrm{mL})$ and LPV $(1.0 \mathrm{mg} / \mathrm{mL})$ and applied separately in triplicate in the form of bands $6 \mathrm{~mm}$ width to reach to a concentration range of 0.8-25.6 for SBR and 0.4-12.8 $\mu \mathrm{g} /$ band for LPV.

The chromatographic procedure described under "Chromatographic Conditions" was then followed. The average of the integrated peak area ratio (peak area of the drug/peak area of an external standard $(1.6 \mu \mathrm{g} / \mathrm{band}$ for SBR and $0.8 \mu \mathrm{g} /$ band for LPV)) was then computed for each concentration of each drug. Two calibration curves were then constructed for SBR and LPV, respectively using the integrated peak area ratios against their corresponding concentrations. The calculation of polynomial regression equations was then performed.

\section{RP HPLC-UV method}

The working standard solutions were used to prepare serial dilutions of both drugs. The linearity range was 6.0-100.0 $\mu \mathrm{g} / \mathrm{mL}$ for SBR and 4.0-80.0 $\mu \mathrm{g} / \mathrm{mL}$ for LPV.
Then, $10 \mu \mathrm{L}$ were injected in triplicate into the system. The relative peak area ratio for each concentration to that of an external standard $(20.0 \mu \mathrm{g} / \mathrm{mL}$ for SBR and $10.0 \mu \mathrm{g} / \mathrm{mL}$ for LPV) was used to construct the calibration graph. Then, the regression equation for each drug was computed.

\section{Laboratory-prepared mixtures assay}

For HPTLC-densitometric method, different aliquots of SBR and LPV were transferred from their respective stock standard solutions and completed to volume with ethanol to prepare a series of laboratory-prepared solutions containing different ratios of both drugs. For RP HPLC-UV, the working standard solutions were used to prepare different concentrations of laboratory prepared mixtures. The concentration of each drug in the laboratory prepared mixtures was calculated by the corresponding regression equation.

\section{Application to their combined pharmaceutical preparation}

Twenty tablets of Heterosofir Plus ${ }^{\odot}$ were grounded and then weighed. A portion of the equivalent to one tablet (400 $\mathrm{mg}$ SBR and $90 \mathrm{mg}$ LPV) was accurately weighed and transferred to a $100-\mathrm{mL}$ volumetric flask, sonicated for $30 \mathrm{~min}$ with $50 \mathrm{~mL}$ of ethanol, and then the volume was completed with the same solvent and filtered to prepare a stock solution, possessing a concentration of $4.00 \mathrm{mg} / \mathrm{mL} \mathrm{SBR}+0.90 \mathrm{mg} / \mathrm{mL} \mathrm{LPV}$.

Accurate aliquots from the stock solution already prepared were applied three times on the TLC plates in the form of bands for the HPTLC-densitometric method. As for RP HPLC-UV method, further dilutions were done using the HPLC mobile phase then injected in triplicate. The concentrations and recoveries were then calculated.

\section{Application of standard addition technique}

The validity and accuracy of the proposed chromatographic methods were also checked by applying the standard addition technique. Three accurately weighed portions of the previously powdered tablets, each claimed to contain $400 \mathrm{mg}$ SBR/90 mg LPV, were mixed with pure standards of SBR and LPV as follows: $200 \mathrm{mg}$ SBR/45 mg LPV, $400 \mathrm{mg}$ SBR/90 mg LPV and $600 \mathrm{mg}$ SBR/135 mg LPV, respectively. Each spiked sample was then transferred to a 100-mL volumetric flask, sonicated for $20 \mathrm{~min}$ in the ultrasonic bath with $20 \mathrm{~mL}$ methanol then the volume was adjusted with the same solvent and filtered to prepare three stock solutions of concentrations: $6.00 \mathrm{mg} /$ $\mathrm{mL} \mathrm{SBR}+1.35 \mathrm{mg} / \mathrm{mL} \mathrm{LPV}, 8.00 \mathrm{mg} / \mathrm{mL} \mathrm{SBR}+1.80 \mathrm{mg} /$ $\mathrm{mL} \mathrm{LPV}$, and $10.00 \mathrm{mg} / \mathrm{mL} \mathrm{SBR}+2.25 \mathrm{mg} / \mathrm{mL} \mathrm{LPV}$.

For HPTLC-densitometric method, $1 \mu \mathrm{L}$ from each spiked sample was then applied onto TLC plates in triplicate. The procedure described above was followed to 
determine the concentration of each drug using their respective regression equations.

For RP HPLC-UV method, the three stock solutions were then further diluted with the mobile phase to reach concentrations within the linear range for each drug. Then, the general procedure described before for RP HPLC-UV method was followed to determine the concentration of both SBR and LPV.

\section{Results and discussion}

The basic target of this research work was to adopt green analytical chemistry through the development of smart chromatographic methods using green solvents, e.g., ethanol instead of the commonly used toxic acetonitrile and toluene instead of the carcinogenic benzene for the simultaneous estimation of SBR and LPV in their co-formulated tablets.

\section{Development and optimization of the proposed chromatographic methods}

The adopted chromatographic procedures were developed and fully optimized with a view to develop eco-friendly reversed-phase HPLC-UV and HPTLC-densitometric methods. The principles, concepts, and fundamentals of green analytical chemistry were considered during trying different solvent systems as mobile phases for the development and optimization of the proposed environmentally green chromatographic methods (Clark and Tavener 2007).

\section{HPTLC-densitometric method}

The separation and quantitative determination of several mixtures could be done by the well-established and highly applied HPTLC accompanied by densitometric detection. In this work, the adopted method depends on the difference in the value of retardation factor $\left(R_{f}\right)$ between SBR and LPV.

In the HPTLC technique, it is common and better to replace hexane with heptane and replace the extremely carcinogenic benzene with toluene (Alfonsi et al. 2008). In order to obtain the best separation with sharp symmetric peaks, various mobile phase systems with different ratios were concisely tried as follows: ethyl acetate: heptane $(2: 8, \mathrm{v} / \mathrm{v})$, acetone: heptane $(4: 6, \mathrm{v} / \mathrm{v})$, toluene: acetone $(4: 1, \mathrm{v} / \mathrm{v})$. On using the first mobile phase system, both drugs fail to be eluted from their places on the plate. Using the second system, the separation among the two drugs was not enhanced to a great extent giving two tailed peaks for both of them. When using toluene, the acetone $(4: 1, \mathrm{v} / \mathrm{v}), \mathrm{SBR}$, and LPV were greatly eluted but had very close $R_{f}$ values. Replacing acetone with ethanol enhanced to high extent the separation between the two drugs but with tailed peaks for SBR. On the addition of ammonia ( 0.2 by volume) to the mobile phase, symmetric, and sharp peaks were obtained with no effect on the separation of the two drugs under this study. Complete and optimum separation of SBR and LPV was achieved by using the mobile phase of toluene: ethanol: ammonia $(4: 1: 0.2, \mathrm{v} / \mathrm{v} / \mathrm{v})$ as a developing system.

In the adopoted HPTLC-densitometric method, toluene proves to be a satisfactory and the best substitute for the carcinogenic benzene (Alfonsi et al. 2008). Scanning wavelength effect on the detection sensitivity of the separation method was also ascertained by testing different scanning wavelengths (254, 260 , and $265 \mathrm{~nm}$ ). Scanning at $265 \mathrm{~nm}$ gave the optimum and best detection sensitivity with minimum noise for the drugs under the study. After the developed method had been fully optimized, compact, sharp, and symmetric peaks were obtained for SBR and LPV with $R_{f}$ values $=0.38$ and 0.61 , respectively as presented in the densitograms in Figs. 2 and 3.

\section{RP HPLC-UV method}

RP-HPLC is the most common separation technique with extensive application used in pharmaceutical industries for drug analysis and quality control. Till today acetonitrile is the most preferred and common organic solvent used in RP-HPLC, and this is due to the optimum physical properties of this organic solvent that are greatly appropriate for HPLC separations (Snyder et al. 1997). Pertaining to the toxic properties of acetonitrile and considering its aqueous waste streams that are typically discarded as chemical waste, it may be the best time to take into account greener replacements for acetonitrile in RP-HPLC. Although methanol is less toxic than acetonitrile, methanol containing streams are also treated as chemical waste. A more easily renewable solvent and ecofriendly such as ethanol (Ribeiro et al. 2004; Capello et al. 2007) could permit for the decrease in the environmental impact of waste solvent removal. Ethanol has been recently adopted for the RP-HPLC analysis of cosmetics as an eco-friendly co-solvent (Salvador and Chisvert 2005). Due to the cost of acetonitrile itself and the resulting cost in its waste elimination continue to increase; the switch to ethanol as a greener alternative (with a reduced cost relative to acetonitrile) becomes greatly compulsory. Another important advantage of the use of ethanol as an HPLC solvent is the worldwide availability of this solvent. The recent increase in the use of ethanol as fuel proposes that the cost and quality of ethanol must continue to get improved in the upcoming years. Finally, the reduced environmental effect of ethanol vs. acetonitrile waste streams is another important consideration arguing in favor of the use of this greener solvent for different HPLC procedures (Welch et al. 2009).

In the present research work, ethanol as a greener solvent was adopted for use in this chromatographic 


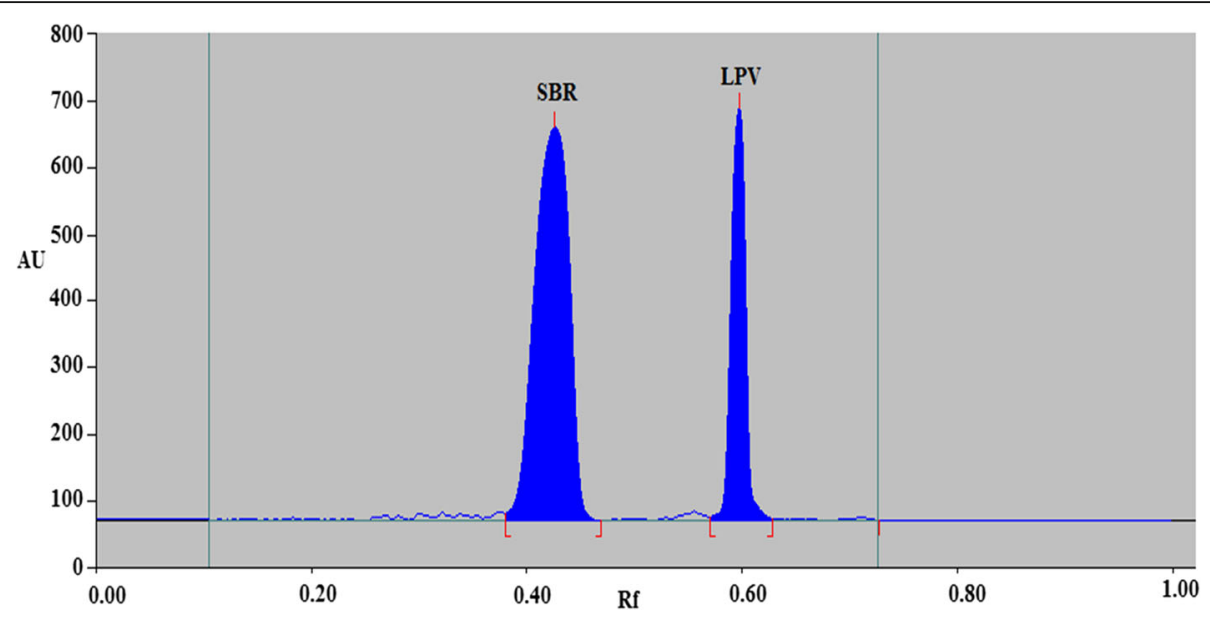

Fig. 2 TLC chromatogram of SBR $\left(12.8 \mu \mathrm{g} / \mathrm{band}, R_{f}=0.38\right)$ and LPV $\left(6.4 \mu \mathrm{g} / \mathrm{band}, R_{f}=0.61\right)$

separation which perfectly replaced acetonitrile. Factors which influence the separation had been concisely studied and fully optimized. Different mobile phases as developing systems had been tried several times to reach the best chromatographic separation for the drugs under the study such as potassium dihydrogen orthophosphate ( $20 \mathrm{mM} ; \mathrm{pH}=3.5$ adjusted by o-phosphoric acid): ethanol $(60: 40, v / v)$. This system separated LPV as a very broad peak. When trying potassium dihydrogen orthophosphate $(20 \mathrm{mM} ; \mathrm{pH}=3.5$ adjusted by o-phosphoric acid): ethanol $(50: 50, \mathrm{v} / \mathrm{v})$ as a mobile phase system, it separated SBR peak with tailing. A satisfactory chromatographic separation and resolution was achieved upon using a mobile phase of potassium dihydrogen orthophosphate $(20 \mathrm{mM} ; \mathrm{pH}=3$ adjusted by acetic acid): ethanol (60:40, v/v) which had produced symmetric sharp peaks without peak broadening or tailing for both drugs. Detection wavelength effect on method sensitivity was also evaluated by trying different scanning wavelengths (254, 260, and $265 \mathrm{~nm})$. Detection wavelength at $265 \mathrm{~nm}$ was found to produce LOD and LOQ of the lowest values. The best chromatographic separation had been developed on Inertsil $C_{18}(4.6 \times 150 \mathrm{~mm}$ with $5 \mu \mathrm{m}$ particle size) using $20 \mathrm{mM}$ potassium dihydrogen orthophosphate (adjusted to $\mathrm{pH}=3$ using acetic acid): ethanol $(60: 40, \mathrm{v} / \mathrm{v})$ as mobile phase system at a flow rate of $1.0 \mathrm{~mL} \mathrm{~min}^{-1}$ and the effluent was monitored at $265 \mathrm{~nm}$. Two peaks were produced at $\mathrm{R}_{\mathrm{t}}: 3.03$ and $4.07 \mathrm{~min}$ for SBR and LPV, respectively, as illustrated in Fig. 4.

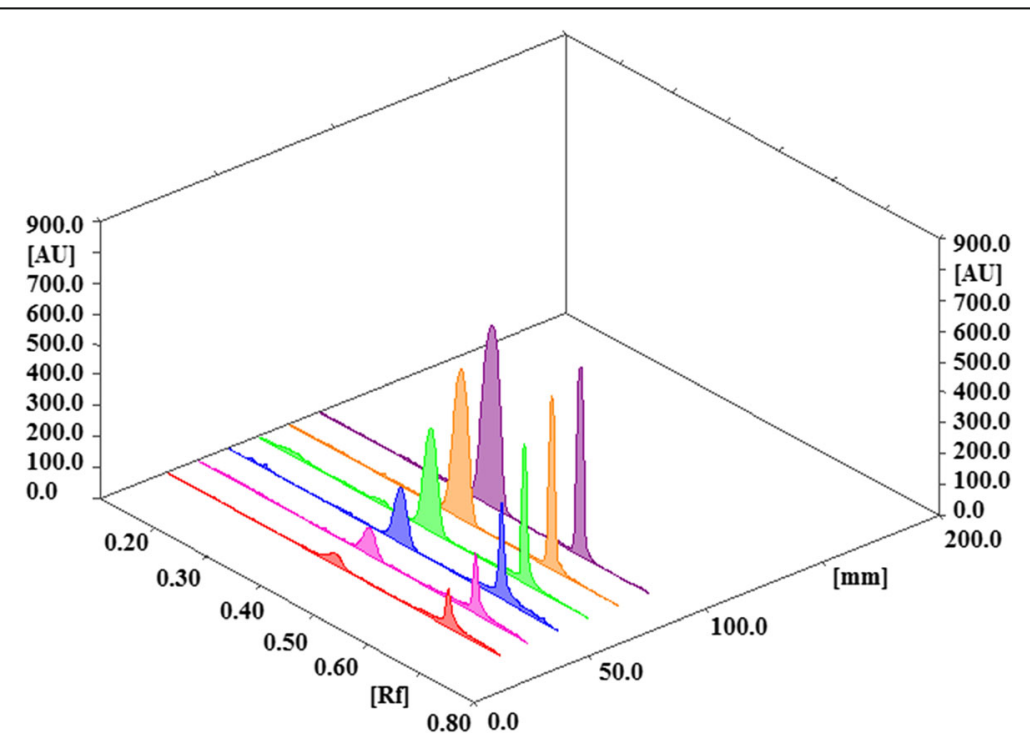

Fig. $33 D$ densitogram of $S B R\left(R_{f}=0.38\right)$ in the concentration range of $0.80-25.6 \mu \mathrm{g} /$ band and $L P V\left(R_{f}=0.61\right)$ in the concentration range of $0.4-$ $12.8 \mu \mathrm{g} /$ band at $265 \mathrm{~nm}$ using toluene: ethanol: ammonia (4:1:0.2, v/v/v) as a developing system 


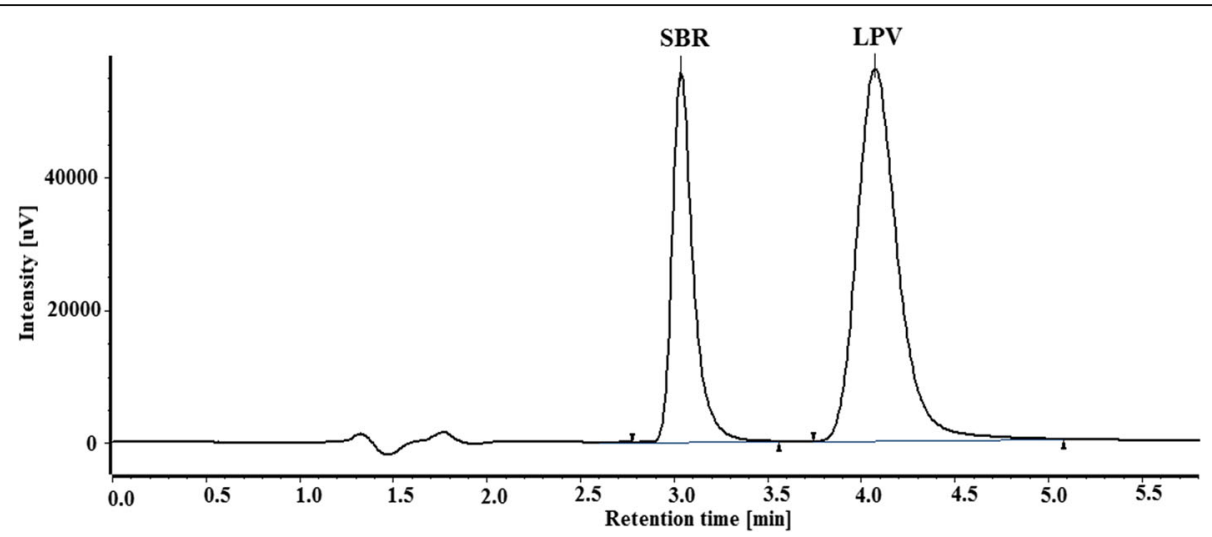

Fig. $4 \mathrm{HPLC}$ chromatogram of $40 \mu \mathrm{g} / \mathrm{mL}$ of SBR and $30 \mu \mathrm{g} / \mathrm{mL}$ of $L P V$

Validation of the developed chromatographic methods $\mathrm{ICH}$ guidelines for method validation ( $\mathrm{ICH} 2005)$ were followed for the adopted methods.

\section{System suitability testing}

System suitability testing was conducted to confirm that the whole operating system performed in a proper way during routine analysis. Each chromatographic procedure was repeated six times, and then the average for each result parameter was calculated. Satisfactory results for the chromatographic methods' performance including capacity factor, resolution, tailing factor, and selectivity were obtained as presented in Table 1.

\section{Linearity and range}

For HPTLC-densitometric method, the relationship between the integrated peak area ratios (using $1.6 \mu \mathrm{g} / \mathrm{band}$ and $0.8 \mu \mathrm{g} / \mathrm{band}$ for SBR and LPV, respectively, as external standard solutions) and different concentrations of each of SBR and LPV was studied with linear and polynomial regression functions. Fitting with polynomial function gave the best correlation with the lowest standard deviation values and was therefore used for the quantitative estimation of SBR and LPV in the range between $0.8-25.6$ and $0.4-12.8 \mu \mathrm{g} /$ band for SBR and LPV, respectively. The polynomial regression of second-order was computed then the regression equations were calculated and found to be:

Table 1 Parameters of system suitability testing of the adopted chromatographic methods for the simultaneous determination of SBR and LPV

\begin{tabular}{|c|c|c|c|}
\hline Parameters & SBR & LPV & Reference value \\
\hline \multicolumn{4}{|l|}{ HPTLC-densitometric method } \\
\hline Retardation factor $\left(R_{f}\right)$ & 0.38 & 0.61 & \\
\hline Resolution ${ }^{\mathrm{a}}\left(R_{s}\right)$ & $4.09^{a}$ & - & $R_{s} \geq 2$ \\
\hline Tailing factor $(T)$ & 0.79 & 0.56 & $T \leq 2$ \\
\hline Capacity Factor ( $\left.K^{\prime}\right)$ & 6.25 & 7.62 & $1<K^{\prime}<10$ \\
\hline Selectivity (a) & $3.61^{a}$ & - & $a>1$ \\
\hline \multicolumn{4}{|l|}{ RP HPLC-UV method } \\
\hline Retention time $\left(R_{t ;}\right.$ min $)$ & 3.03 & 4.07 & \\
\hline Resolution ${ }^{\mathrm{a}}\left(R_{s}\right)$ & 3.58 & & $R_{s} \geq 2$ \\
\hline Tailing factor $(T)$ & 1.49 & 1.26 & $T \leq 2$ \\
\hline Asymmetry factor $\left(A_{f}\right)$ & 1.04 & 1.00 & $0.9<A_{f}<1.1$ \\
\hline Capacity Factor ( $\left.K^{\prime}\right)$ & 1.32 & 2.12 & $1<K^{\prime}<10$ \\
\hline Selectivity (a) & $1.60^{\mathrm{a}}$ & - & $a>1$ \\
\hline Injection repeatability ${ }^{\mathrm{b}}$ & 0.83 & 0.75 & $R S D \leq 1 \%$ for $n \geq 6$ \\
\hline Theoretical plates $(N)$ & 3936 & 2108 & $N>2000$ \\
\hline Height equivalent to theoretical plate (HETP; $\mathrm{cm}$ plate ${ }^{-1}$ ) & 0.0038 & 0.0071 & The smaller the value, the higher the column efficiency \\
\hline
\end{tabular}




$$
\begin{array}{rlr}
\mathrm{A}_{1} & =-0.0223 \mathrm{C}_{1}^{2}+1.0976 \mathrm{C}_{1}+0.3402 \mathrm{r}_{1} \\
& =0.9998 \text { For SBR } \\
& \\
\mathrm{A}_{2} & =-0.0248 \mathrm{C}_{2}^{2}+0.6093 \mathrm{C}_{2}+0.5385 \mathrm{r}_{2} \\
& =0.9998 \text { For LPV }
\end{array}
$$

Where $A_{1}$ and $A_{2}$ are the integrated peak area ratios, $C_{1}$ and $C_{2}$ are the concentrations in $\mu \mathrm{g} / \mathrm{band}$, and $r_{1}, r_{2}$ are the correlation coefficients of SBR and LPV, respectively.

For RP HPLC-UV method, calibration graphs were constructed by plotting the integrating peak area ratios (using $20.0 \mu \mathrm{g} / \mathrm{mL}$ for SBR and $10.0 \mu \mathrm{g} / \mathrm{mL}$ for LPV as external standard solutions) versus their corresponding concentrations in the range of $10.0-100.0 \mu \mathrm{g} / \mathrm{mL}$ for SBR and $5.0-80.0 \mu \mathrm{g} / \mathrm{mL}$ for LPV. Then the linear regression equations were computed for each of SBR and LPV and were found to be:

$$
\begin{array}{lll}
\mathrm{A}_{1}=0.0454 \mathrm{C}_{1}+0.0283 & \mathrm{r}_{1}=0.9996 & \text { For SBR } \\
\mathrm{A}_{2}=0.1031 \mathrm{C}_{2}-0.0257 & \mathrm{r}_{2}=0.9998 & \text { For LPV }
\end{array}
$$

Where $A_{1}$ and $A_{2}$ are the integrated peak area ratios, $\mathrm{C}_{1}$ and $\mathrm{C}_{2}$ are the concentrations in $\mu \mathrm{g} / \mathrm{mL}$, and $r_{1}$ and $\mathrm{r}_{2}$ are the correlation coefficients of SBR and LPV, respectively.

Regression data analysis was computed for both HPTLCdensitometric and RP HPLC-UV methods data sets of SBR and LPV using residual data plots, line fit data plots and normal probability plots as shown in Figs. 5 and 6. The regression equations characteristic parameters of the adopted chromatographic methods are presented in Table 2.

\section{Limit of detection and limit of quantitation}

As per ICH recommendations, various approaches for determining the lower limits of detection and quantitation are applicable. The calculation approach using standard deviation value of the intercept and the slope value was conducted to compute limits of detection and quantitation, in which:

$$
\begin{aligned}
& \mathrm{LOD}=3.3 \times \mathrm{SD} \text { of intercept} / \text { slope coefficient } \\
& \mathrm{LOQ}=10 \times \mathrm{SD} \text { of intercept } / \text { slope coefficient }
\end{aligned}
$$

Low values for limit of detection (LOD) and limit of quantitation (LOQ) presented in Table 2 indicated the high sensitivity of the adopted chromatographic methods.

\section{Accuracy}

Accuracy of the proposed chromatographic methods was checked by testing different samples of pure SBR and LPV. The respective regression equation computed in each of the adopted methods for each drug was used to calculate their concentrations and the data results are presented in Table 2 .
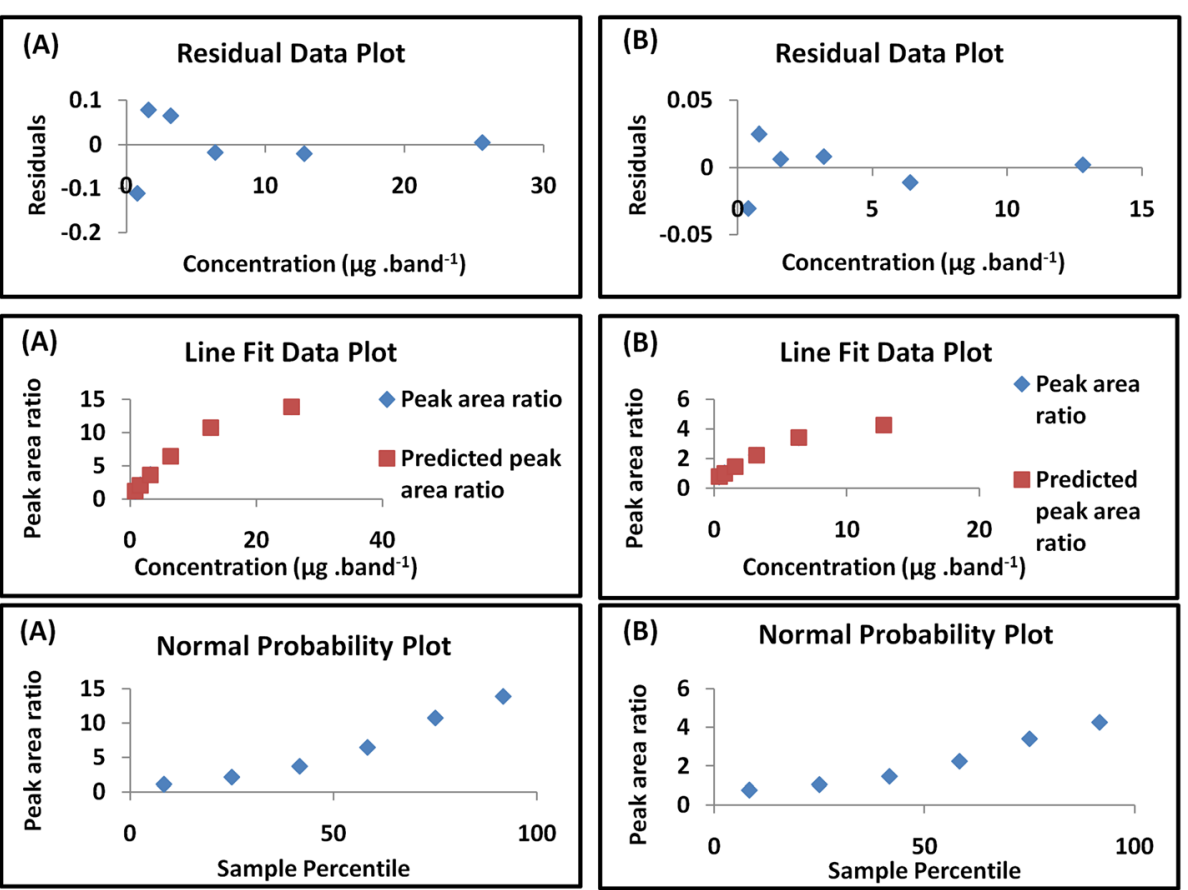

Fig. 5 Residual data plot, line fit data plot, and normal probability plot for SBR (a) and LPV (b) in HPTLC-densitometric method 

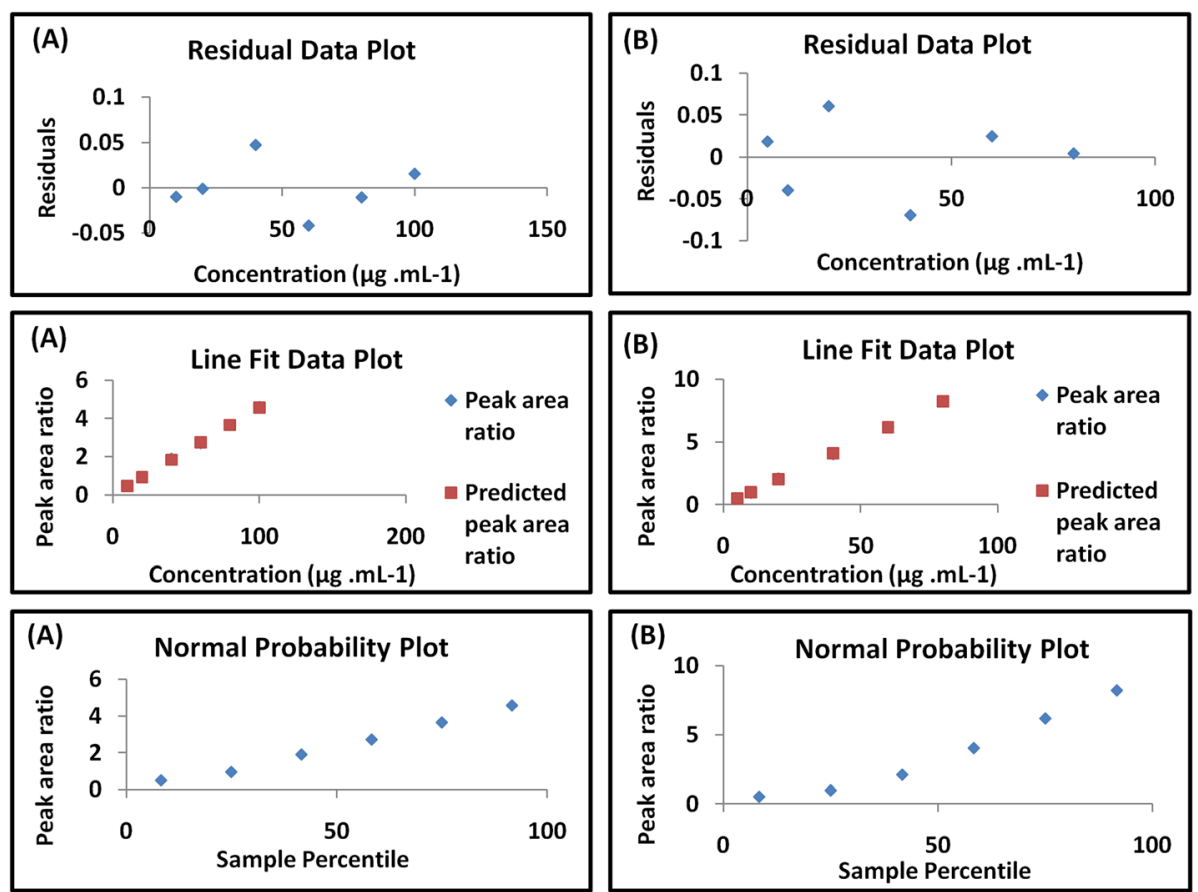

Fig. 6 Residual data plot, line fit data plot, and normal probability plot for SBR (a) and LPV (b) in RP HPLC-UV method

\section{Precision}

Intra-day Three concentrations (1.6, 6.4, and $12.8 \mu \mathrm{g} / \mathrm{band})$ of SBR and (0.8, 3.2, and 6.4 $\mu \mathrm{g} / \mathrm{band})$ of LPV for HPTLCdensitometric method and $(20.0,40.0$, and $80.0 \mu \mathrm{g} / \mathrm{mL})$ of
SBR and (10.0, 20.0, and $60.0 \mu \mathrm{g} / \mathrm{mL}$ ) of LPV for RP HPLCUV method were tested in the same day three times using the developed chromatographic methods. Satisfactory \% RSD values were obtained which confirmed the repeatability of the adopted methods as presented in Table 2 .

Table 2 Validation parameters of the regression equations and assay results of the proposed chromatographic methods for the simultaneous quantitation of SBR and LPV

\begin{tabular}{|c|c|c|c|c|}
\hline \multirow[t]{2}{*}{ Validation parameters } & \multicolumn{2}{|c|}{ HPTLC-densitometric method } & \multicolumn{2}{|l|}{ RP HPLC-UV method } \\
\hline & SBR & LPV & SBR & LPV \\
\hline Linearity range & $0.8-25.6\left(\mu \mathrm{g}\right.$ band $\left.^{-1}\right)$ & 0.4-12.8 $\left(\mu \mathrm{g}\right.$ band $\left.^{-1}\right)$ & $6.00-100.00\left(\mu \mathrm{g} \mathrm{m}^{-1}\right)$ & $4.0-80.0\left(\mu \mathrm{g} \mathrm{m}^{-1}\right)$ \\
\hline Slope ( $X^{2}$ coefficient) & -0.0223 & -0.0248 & - & - \\
\hline SE of Slope ( $X^{2}$ coefficient) & 0.0006 & 0.0007 & - & - \\
\hline Slope (X coefficient) & 1.0976 & 0.6093 & 0.0454 & 0.1031 \\
\hline SE of slope (X coefficient) & 0.0170 & 0.0094 & 0.0004 & 0.0008 \\
\hline Intercept & 0.3402 & 0.5385 & 0.0283 & -0.0257 \\
\hline SE of intercept & 0.0688 & 0.0191 & 0.0258 & 0.0353 \\
\hline Correlation coefficient (r) & 0.9998 & 0.9998 & 0.9996 & 0.9998 \\
\hline LOD & $0.21\left(\mu \mathrm{g}\right.$ band $\left.^{-1}\right)$ & $0.10\left(\mu \mathrm{g}\right.$ band $\left.^{-1}\right)$ & $1.88\left(\mu \mathrm{g} \mathrm{m}^{-1}\right)$ & $1.13\left(\mu \mathrm{g} \mathrm{m}^{-1}\right)$ \\
\hline LOQ & $0.63\left(\mu \mathrm{g}\right.$ band $\left.^{-1}\right)$ & $0.31\left(\mu \mathrm{g}\right.$ band $\left.^{-1}\right)$ & $5.69\left(\mu \mathrm{g} \mathrm{m}^{-1}\right)$ & $3.42\left(\mu \mathrm{g} \mathrm{m}^{-1}\right)$ \\
\hline Accuracy ${ }^{a}$ & $99.78 \pm 0.970$ & $100.04 \pm 1.090$ & $99.87 \pm 1.270$ & $99.64 \pm 1.190$ \\
\hline \multicolumn{5}{|l|}{ Precision ${ }^{b}$} \\
\hline Intra-day & 0.575 & 0.862 & 0.613 & 1.276 \\
\hline Inter-day & 1.274 & 1.543 & 1.628 & 1.903 \\
\hline
\end{tabular}

${ }^{\mathrm{a}}$ Mean $\pm \mathrm{SD}$

${ }^{\mathrm{b}} \mathrm{RSD} \%, n=9$ 
Inter-day The chromatographic procedures mentioned above were conducted on three different days for the quantification of the three chosen concentrations of SBR and LPV. Satisfactory values for \% RSD were obtained as illustrated in Table 2.

\section{Specificity}

Method specificity was tested by how accurately, precisely, and specifically the drug of interest is estimated in presence of other components (e.g., co-formulated drugs, impurities, related substances, or possible degradation products). This is assured from HPTLC 2D and 3D densitograms presented in Figs. 2 and 3, respectively, and HPLC chromatogram shown in Fig. 4 which gives the evidence of the optimum specificity of the adopted methods. Accepted results presented in Table 3 indicate the good specificity of the adopted chromatographic methods for the simultaneous determination of SBR and LPV in different proportions.

\section{Robustness}

Analytical method robustness is its capability to remain uninfluenced with small deliberate changes in method parameters which gives an adequate indication of the reliability of the proposed chromatographic method during routine work, e.g., changing mobile phase ratio $( \pm$ $0.2 \mathrm{~mL}$ ) for HPTLC-densitometric method and changing mobile phase ratio $( \pm 2.0 \mathrm{~mL})$ and $\mathrm{pH}$ of the mobile phase ( \pm 0.1 unit) in RP HPLC-UV method. The low \% RSD values show that the adopted chromatographic methods are robust and that the deliberate minor changes in the chromatographic factors mentioned above produced no significant changes in $R_{t}$ or $R_{f}$ values, $\mathrm{T}, \mathrm{N}$, and Rs of the chromatographed peaks as presented in Table 4.

\section{Application to their combined pharmaceutical preparation}

The adopted chromatographic methods were then applied for the determination of SBR and LPV in their combined tablet dosage form. The obtained results were acceptable and satisfactory with low values of $\%$ RSD as shown in Table 5.

Moreover, validity and accuracy of the proposed chromatographic methods were also confirmed by standard addition technique application where satisfactory recoveries were obtained which assured that there was not any interference due to added excipients in the tablet matrix, as illustrated in Table 6.

\section{Statistical comparison to an in-house method}

The statistical comparison of the data results obtained from the application of the suggested chromatographic methods with those obtained from the application of a
Table 3 Simultaneous determination of SBR and LPV in laboratory prepared mixtures by the developed chromatographic methods

\begin{tabular}{|c|c|c|c|}
\hline \multicolumn{4}{|c|}{ HPTLC-densitometric method } \\
\hline \multicolumn{2}{|c|}{ Laboratory-prepared mixture } & \multicolumn{2}{|l|}{$\%$ Recovery $^{a}$} \\
\hline $\operatorname{SBR}\left(\mu \mathrm{g}\right.$ band $\left.^{-1}\right)$ & LPV $\left(\mu \mathrm{g}\right.$ band $\left.^{-1}\right)$ & SBR & LPV \\
\hline 8.00 & 0.90 & 98.53 & 100.43 \\
\hline 4.00 & 1.80 & 99.72 & 99.92 \\
\hline 4.00 & 0.90 & 100.99 & 98.99 \\
\hline 4.00 & 0.45 & 99.81 & 101.01 \\
\hline 2.00 & 0.90 & 101.11 & 98.81 \\
\hline Mean \pm SD $\%$ & & $100.03 \pm 1.059$ & $99.83 \pm 0.936$ \\
\hline \multicolumn{4}{|c|}{ RP HPLC-UV method } \\
\hline \multicolumn{2}{|c|}{ Laboratory-prepared mixture } & \multicolumn{2}{|l|}{$\%$ Recovery $^{\mathrm{a}}$} \\
\hline $\operatorname{SBR}\left(\mu \mathrm{g} \mathrm{ml}^{-1}\right)$ & $\operatorname{LPV}\left(\mu \mathrm{g} \mathrm{ml}^{-1}\right)$ & SBR & LPV \\
\hline 80.00 & 9.00 & 98.14 & 98.17 \\
\hline 40.00 & 18.00 & 99.32 & 98.92 \\
\hline 40.00 & 9.00 & 99.72 & 99.57 \\
\hline 40.00 & 4.50 & 100.38 & 98.72 \\
\hline 20.00 & 9.00 & 98.61 & 98.61 \\
\hline Mean \pm SD $\%$ & & $99.23 \pm 0.886$ & $98.80 \pm 0.512$ \\
\hline
\end{tabular}

${ }^{a}$ Average of 3 experiments

reported RP-HPLC method (Rote et al. 2017) presented no significant statistical difference with confidence limit of $95 \%$ in concern of both accuracy and precision as described in Table 7.

\section{Conclusion}

The plan for the replacement of the traditional widelyused toxic solvents and chemicals with less toxic and inert ones presents environmentally benign alternatives to the most toxic ones in the pharmaceutical analysis field. This study demonstrates that the developed

Table 4 Robustness testing ${ }^{a}$ of the adopted chromatographic methods for the simultaneous estimation of SBR and LPV

\begin{tabular}{|c|c|c|c|c|c|c|c|}
\hline \multicolumn{8}{|c|}{ HPTLC-densitometric method } \\
\hline \multirow[t]{2}{*}{ Condition } & \multicolumn{4}{|l|}{ SBR } & \multicolumn{3}{|l|}{ LPV } \\
\hline & $R_{f}$ & $\mathrm{~T}$ & & $R_{s}^{b}$ & $\mathrm{R}_{\mathrm{f}}$ & $\mathrm{T}$ & \\
\hline $\begin{array}{l}\text { Mobile phase ratio }( \pm \\
0.2 \mathrm{~mL})\end{array}$ & 1.501 & 1.315 & & 1.513 & 1.412 & 1.543 & \\
\hline \multicolumn{8}{|l|}{ RP HPLC-UV method } \\
\hline \multirow[t]{2}{*}{ Condition } & SBR & & & & LPV & & \\
\hline & $\mathrm{R}_{\mathrm{t}}$ & $\mathrm{T}$ & $\mathrm{N}$ & $\mathrm{R}_{\mathrm{s}}^{\mathrm{b}}$ & $\mathrm{R}_{\mathrm{t}}$ & $\mathrm{T}$ & $\mathrm{N}$ \\
\hline $\begin{array}{l}\text { Mobile phase ratio }( \pm \\
2.0 \mathrm{~mL})\end{array}$ & 0.796 & 0.317 & 0.398 & 1.573 & 0.843 & 0.486 & 1.059 \\
\hline $\begin{array}{l}\mathrm{pH} \text { of of the mobile } \\
\text { phase ( } \pm 0.1 \text { unit) }\end{array}$ & 0.264 & 0.341 & 0.486 & 1.583 & 0.386 & 0.563 & 1.251 \\
\hline
\end{tabular}


Table 5 Simultaneous estimation of SBR and LPV in Heterosofir Plus ${ }^{\circledR}$ tablets using the adopted chromatographic methods

\begin{tabular}{|c|c|c|c|c|c|c|c|}
\hline \multicolumn{8}{|l|}{ HPTLC-densitometric method } \\
\hline \multirow[t]{2}{*}{ Pharmaceutical preparation } & \multirow[t]{2}{*}{$\begin{array}{l}\text { Sample } \\
\text { no. }\end{array}$} & \multicolumn{2}{|c|}{$\begin{array}{l}\text { Taken } \\
\text { amount } \\
\left(\mu \mathrm{g} \text { band }^{-1}\right)\end{array}$} & \multicolumn{2}{|c|}{$\begin{array}{l}\text { Found }^{\mathrm{a}} \\
\text { amount } \\
\left(\mu \mathrm{g} \text { band }^{-1}\right)\end{array}$} & \multicolumn{2}{|l|}{$\%$ Recovery } \\
\hline & & SBR & LPV & SBR & LPV & SBR & LPV \\
\hline \multirow{4}{*}{$\begin{array}{l}\text { Heterosofir Plus }{ }^{\oplus} \text { tablets labeled to contain } 400 \text { mg SRB }+90 \text { mg LPV per } \\
\text { tablet }\end{array}$} & 1 & 4.00 & 0.90 & 4.02 & 0.90 & 100.50 & 100.00 \\
\hline & 2 & 8.00 & 1.80 & 8.10 & 1.79 & 101.25 & 99.44 \\
\hline & 3 & 16.00 & 3.60 & 15.92 & 3.62 & 99.50 & 100.56 \\
\hline & \multicolumn{3}{|c|}{ Mean $\pm \%$ RSD } & & & $\begin{array}{l}100.42 \pm \\
0.878\end{array}$ & $\begin{array}{l}100.00 \pm \\
0.556\end{array}$ \\
\hline \multicolumn{8}{|l|}{ RP HPLC-UV method } \\
\hline \multirow[t]{2}{*}{ Pharmaceutical preparation } & \multirow[t]{2}{*}{$\begin{array}{l}\text { Sample } \\
\text { no. }\end{array}$} & \multicolumn{2}{|c|}{$\begin{array}{l}\text { Taken } \\
\text { amount } \\
\left(\mu \mathrm{g} \cdot \mathrm{ml}^{-1}\right)\end{array}$} & \multicolumn{2}{|c|}{$\begin{array}{l}\text { Found }^{\mathrm{a}} \\
\text { amount } \\
\left(\mu \mathrm{g} \cdot \mathrm{ml}^{-1}\right)\end{array}$} & \multicolumn{2}{|l|}{$\%$ Recovery } \\
\hline & & SBR & LPV & SBR & LPV & SBR & LPV \\
\hline \multirow{4}{*}{$\begin{array}{l}\text { Heterosofir Plus }{ }^{\oplus} \text { tablets labeled to contain } 400 \text { mg SRB + } 90 \text { mg LPV per } \\
\text { tablet }\end{array}$} & 1 & 20.00 & 4.50 & 20.14 & 4.51 & 100.70 & 100.22 \\
\hline & 2 & 40.00 & 9.00 & 40.03 & 8.83 & 100.08 & 98.11 \\
\hline & 3 & 80.00 & 18.00 & 79.52 & 17.92 & 99.40 & 99.56 \\
\hline & \multicolumn{3}{|c|}{ Mean $\pm \%$ RSD } & & & $\begin{array}{l}100.06 \pm \\
0.650\end{array}$ & $99.30 \pm 1.079$ \\
\hline
\end{tabular}

chromatographic methods using green solvents are found to be quite specific, sensitive, accurate, reproducible, and precise. Satisfactory results for method validation parameters can encourage the use of greener analytical approaches in quality control field. The proposed HPTLC-densitometric and RP HPLC-UV methods can be used in quality control laboratories for the routine analysis and the simultaneous quantitative determination of SBR and LPV in their combined dosage form (Hetersofir Plus ${ }^{\circ}$ ). The well-known advantages of the HPTLC-densitometric method is that different samples can be run simultaneously using a small volume of the mobile phase system with short run time while RP HPLC-UV method offers optimum resolution, good specificity, higher sensitivity and wider range of quantitation over previously published and reported

Table 6 Results of standard addition technique application on Heterosofir Plus ${ }^{\circledR}$ tablets to the simultaneous analysis of SBR and LPV using the proposed chromatographic methods

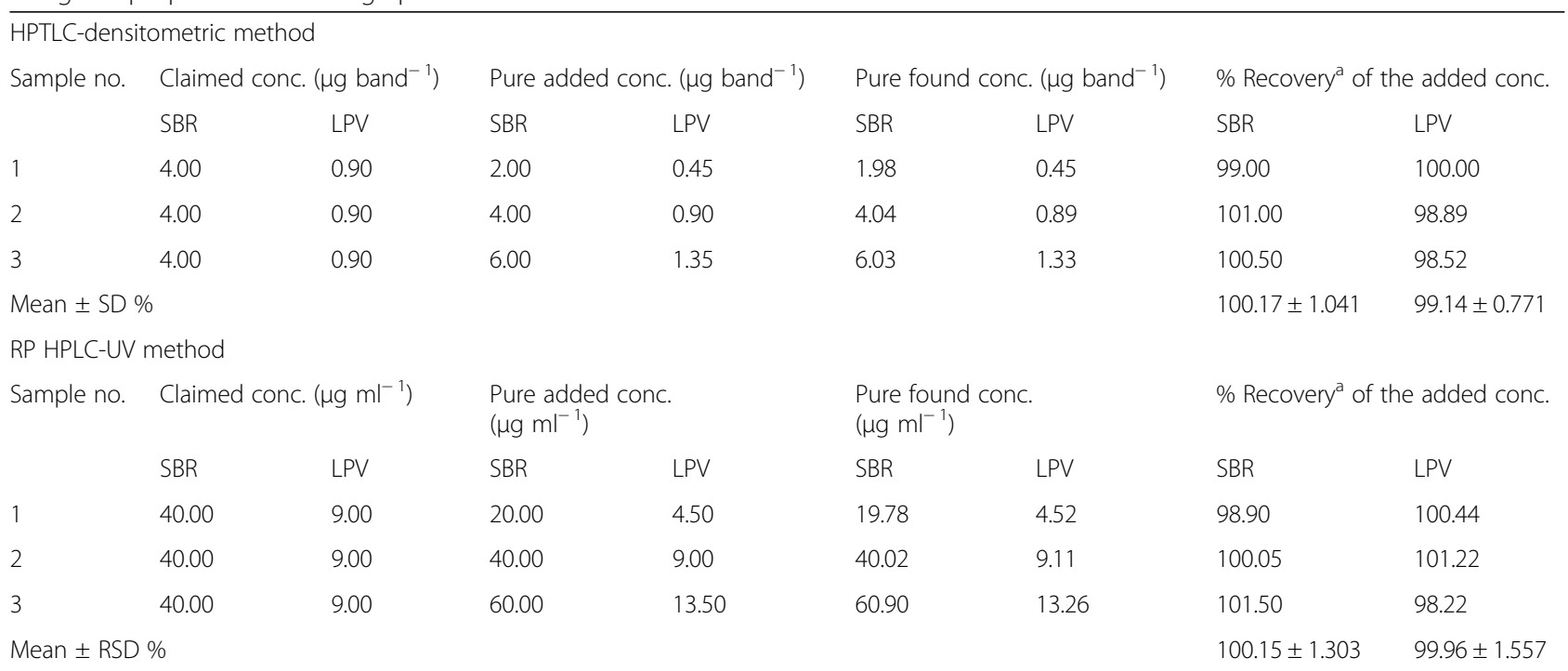


Table 7 Results of statistical comparison ${ }^{\text {a }}$ between the developed chromatographic methods and reported HPLC method (Rote et al. 2017) used for the simultaneous determination of SBR and LPV

\begin{tabular}{|c|c|c|c|c|c|c|}
\hline \multirow[t]{2}{*}{ Parameters } & \multicolumn{2}{|c|}{ Proposed HPTLC-densitometric method } & \multicolumn{2}{|c|}{ Proposed RP HPLC-UV method } & \multicolumn{2}{|c|}{ In-house HPLC method ${ }^{b}$} \\
\hline & SBR & LPV & SBR & LPV & SBR & LPV \\
\hline Mean & 99.78 & 100.04 & 99.87 & 99.64 & 100.90 & 100.08 \\
\hline SD & 0.970 & 1.090 & 1.270 & 1.190 & 0.835 & 0.553 \\
\hline Variance & 0.941 & 1.188 & 1.613 & 1.416 & 0.697 & 0.306 \\
\hline$t$ test $^{\mathrm{a}}$ & 1.957 & 0.073 & 1.515 & 0.750 & - & \\
\hline F-test ${ }^{a}$ & 1.349 & 3.885 & 2.313 & 4.631 & - & \\
\hline
\end{tabular}

${ }^{a}$ The theoretical values of $t$ and $F$ at $P=0.05$ are (2.306) and (6.388), respectively where $n=5$

${ }^{b}$ RP-HPLC method was performed on the Systronics isocratic HPLC system equipped with SP930 D HPLC pump and dual wavelength UV-VIS detector and C18 column $(250 \mathrm{~mm} \times 4.6 \mathrm{~mm}, 5 \mu \mathrm{m})$, using the mobile phase (Methanol: Water $83: 17 \mathrm{v} / \mathrm{v}) \mathrm{pH} 3.0$ with $0.05 \%$ acidic acid at a flow rate of $1.0 \mathrm{ml} / \mathrm{min}$, injection volume $20 \mu \mathrm{l}$ and UV detection at $245 \mathrm{~nm}$

HPLC methods with the desired accuracy and reproducibility through reasonable analysis time. An important conclusion of this study is that these green eluents have the ability to be used for different analyses in chromatographic science and thus making the separation process more ecofriendly to the surrounding environment. Safer alternatives should be studied on the basis of their safety, health, life cycle, and environmental assessment to replace the traditional hazardous solvent adopting green separation science because developing green analytical methods to replace the traditional ones becomes a very important requirement. The use of a greener solvent such as ethanol would be strongly preferred for such applications.

\section{Abbreviations \\ DAD: Diode array; HPLC: High-performance liquid chromatography; HPTLC: High-performance thin layer chromatography; ICH: International Conference on Harmonization; LOD: Limit of detection; LOQ: Limit of quantification; LPV: Ledipasvir; MS/MS: Tandem mass; Rf: Retardation factor; RP: Reversed phase; RSD: Relative standard deviation; $\mathrm{R}_{\mathrm{t}}$ : Retention time; SBR: Sofosbuvir; SD: Standard deviation; UV: Ultraviolet}

\section{Acknowledgements}

Not applicable.

\section{Authors' contributions}

Both AH and MSE participated in the design of the study. AH carried out HPLCUV method, performed the validation parameters and the statistical analysis for the method and helped to draft the manuscript while MSE carried out HPTLCdensitometry method, performed the validation parameters and the statistical analysis for the method and put the manuscript in the final form for journal submission. All authors read and approved the final manuscript.

\section{Funding}

The authors receive no fund to develop this study.

\section{Availability of data and materials}

Not applicable.

Ethics approval and consent to participate

Not applicable.

\section{Consent for publication}

Not applicable.

\section{Competing interests}

The authors declare that they have no competing interests.

\section{Author details}

${ }^{1}$ Department of Pharmaceutical Analytical Chemistry, Faculty of Pharmacy, Ahram Canadian University, Giza, Egypt. ²Department of Pharmaceutical Analytical Chemistry, Faculty of Pharmacy, Egyptian Russian University, Cairo, Egypt.

Received: 6 September 2019 Accepted: 8 November 2019

Published online: 30 December 2019

\section{References}

Afdhal N, Zeuzem S, Kwo P, Chojkier M, Gitlin N, Puoti M, Romero-Gomez M, Zarski J-P, Agarwal K, Buggisch P. Ledipasvir and sofosbuvir for untreated HCV genotype 1 infection. New Engl J Med. 2014;370(20):1889-98.

Alfonsi K, Colberg J, Dunn PJ, Fevig T, Jennings S, Johnson TA, Kleine HP, Knight C, Nagy MA, Perry DA. Green chemistry tools to influence a medicinal chemistry and research chemistry based organisation. Green Chem. 2008; 10(1):31-6.

Baker MM, El-Kafrawy DS, Mahrous MS, Belal TS. Validated spectrophotometric and chromatographic methods for analysis of the recently approved hepatitis C antiviral combination ledipasvir and sofosbuvir. Ann Pharm Fr. 2018;76(1):16-31

Capello C, Fischer U, Hungerbühler K. What is a green solvent? A comprehensive framework for the environmental assessment of solvents. Green Chem. 2007; 9(9):927-34.

Clark JH, Tavener SJ. Alternative solvents: shades of green. Org Process Res Dev. 2007;11(1):149-55.

Elkady EF, Aboelwafa AA. A rapid and optimized LC-MS/MS method for the simultaneous extraction and determination of sofosbuvir and ledipasvir in human plasma. J AOAC Int. 2016;99(5):1252-9.

Farid NF, Abdelwahab NS. Chromatographic analysis of ledipasvir and sofosbuvir: new treatment for chronic hepatitis $C$ infection with application to human plasma. J Liq Chromatogr Relat Technol. 2017;40(7):327-32.

Gorman, E.; Mogalian, E.; Oliyai, R.; Stefanidis, D.; Wiser, L.; Zia, V. (2015). Combination formulation of two antiviral compounds. U.S. Patent, 14/ $168,340$.

Hassouna ME, Abdelrahman MM, Mohamed MA. Assay and dissolution methods development and validation for simultaneous determination of sofosbuvir and ledipasvir by RP-HPLC method in tablet dosage forms. J Forensic Sci \& Criminal Inves. 2017;1(3):555-62.

ICH, Q2 (R1) Validation of analytical procedures: text and methodology, Proceeding of The International Conference on Harmonization, Geneva, 2005.

Jacobson IM, Davis GL, El-Serag H, Negro F, Trépo C. Prevalence and challenges of liver diseases in patients with chronic hepatitis $C$ virus infection. Clin Gastroenter Hepat. 2010;8(11):924-33.

Keating GM, Vaidya A. Sofosbuvir: first global approval. Drugs. 2014;74(2):273-82.

Lavanchy D. Evolving epidemiology of hepatitis C virus. Clin Microbiol Infec. 2011;17(2):107-15.

Link JO, Taylor JG, Xu L, Mitchell M, Guo H, Liu H, Kato D, Kirschberg T, Sun J, Squires N. Discovery of ledipasvir (GS-5885): a potent, once-daily oral NS5A 
inhibitor for the treatment of hepatitis C virus infection. J Med Chem. 2014; 57(5):2033-46.

Pan C, Chen Y, Chen W, Zhou G, Jin L, Zheng Y, Lin W, Pan Z. Simultaneous determination of ledipasvir, sofosbuvir and its metabolite in rat plasma by UPLC-MS/MS and its application to a pharmacokinetic study. J Chromatogr B. 2016;1008:255-9.

Pollack A. Harvoni, a hepatitis C drug from Gilead, wins FDA approval. New York Times. 2014;10:10-4.

Rezk MR, Bendas ER, Basalious EB, Karim IA. Quantification of sofosbuvir and ledipasvir in human plasma by UPLC-MS/MS method: application to fasting and fed bioequivalence studies. J Chromatogr B. 2016;1028:63-70.

Ribeiro RL, Bottoli CB, Collins KE, Collins CH. Reevaluation of ethanol as organic modifier for use in HPLS-RP mobile phases. J Braz Chem Soc. 2004;15(2):300-6.

Rote AP, Alhat J, Kulkarni AA. Development and validation of RP-HPLC method for the simultaneous estimation of ledipasvir and sofosbuvir in bulk and pharmaceutical dosage form. Int J Pharm Sci Drug Res. 2017;9(6):291-8.

Salama FM, Attia KA, Abouserie AA, El-Olemy A, Abolmagd E. Application of TLC densitometric method for simultaneous estimation of the newly coformulated antiviral agents ledipasvir and sofosbuvir in their tablet dosage form. Analytical Chem Letters. 2017;7(2):241-7.

Salvador A, Chisvert A. An environmentally friendly ("green") reversed-phase liquid chromatography method for UV filters determination in cosmetics. Anal Chim Acta. 2005;537(1):15-24.

Snyder LR, Kirkland JJ, Glajch JL. Completing the method: validation and transfer, in practical HPLC method development. 2nd ed. Hoboken: Wiley; 1997. p. 685-713.

Welch CJ, Brkovic T, Schafer W, Gong X. Performance to burn? Re-evaluating the choice of acetonitrile as the platform solvent for analytical HPLC. Green Chem. 2009;11(8):1232-8.

Welch CJ, Wu N, Biba M, Hartman R, Brkovic T, Gong X, Helmy R, Schafer W, Cuff J, Pirzada Z. Greening analytical chromatography. TrAC Trends Anal Chem. 2010;29(7):667-80.

Zaman B, Siddique F, Hassan W. RP-HPLC method for simultaneous determination of Sofosbuvir and Ledipasvir in tablet dosage form and its application to in vitro dissolution studies. Chromatographia. 2016;79(23-24): 1605-13.

\section{Publisher's Note}

Springer Nature remains neutral with regard to jurisdictional claims in published maps and institutional affiliations.

\section{Submit your manuscript to a SpringerOpen ${ }^{\circ}$ journal and benefit from:}

- Convenient online submission

- Rigorous peer review

- Open access: articles freely available online

- High visibility within the field

- Retaining the copyright to your article

Submit your next manuscript at $\boldsymbol{\nabla}$ springeropen.com 